\title{
Food for Thought ... on the Economics of Animal Testing
}

\author{
Annamaria A. Bottini ${ }^{1,3}$ and Thomas Hartung ${ }^{2,4}$ \\ EU Joint Research Centre, Ispra, Italy, ${ }^{1}$ ISD and ${ }^{2}$ IPSC / TRiVA, ${ }^{3}$ European School of Economics, Milan, Italy, ${ }^{4}$ Center for \\ Alternatives to Animal Testing, Johns Hopkins University, Baltimore, USA
}

\begin{abstract}
"Money makes the world go around." We all know the truth in this line from the movie "Cabaret", but in the field of alternative methods we talk about ethics, scientific progress, politics, animal welfare or consumer and environmental safety but rarely about money. In this series of articles, we have occasionally touched on issues that are difficult to separate from economic aspects. Most obviously, the article on globalisation (Bottini et al., 2007) showed the resonance between a major economic trend and recent developments in the field of alternative methods. Most recently, the articles on cosmetics and food safety testing in this series included aspects of regulation and economic impact (Hartung, 2008b; Hartung and Koeter, 2008). Last but not least, the article on animal experimentation (Hartung, 2008a) touched on the economic implications of animal testing. Now, we would like to expand on the economic forces influencing the field of alternative methods. This requires a review of the major industries regulated by animal testing, differences between the nations, functions of animal testing in the economic cycle, alternative methods as a market, and costs of limitations of current practices and economic forces, which might force change.

Alfred A. Knopf stated "An economist is a man who states the obvious in terms of the incomprehensible" and John Kenneth Galbraith said "Economics is extremely useful as a form of employment for economists". By combining our scientific and legal/economical expertise, the authors aim to formulate some
\end{abstract}

considerations that are not completely obvious and to express them comprehensibly. As always, we encourage comments and replies to see whether this so far largely neglected topic delivers helpful insights.

\section{Consideration 1: The "regulated communities" relying on animal testing are heterogeneous}

The first step towards understanding the economic mechanisms of animal testing is to analyse which industrial sectors use animal testing and to what extent. This assessment omits animal experimentation for basic research, i.e. $33 \%$ of all animal use (European Commission, 2007). However, to some extent, basic research will follow industrial needs and priorities mainly via research funding. Some opportunities for improvement in this area have been discussed previously (Gruber and Hartung, 2004). Here, we will focus mainly on regulatory testing $(23.3 \%$ of all animal use (European Commission, 2007), i.e. $8 \%$ for toxicology and safety assessments and $15.3 \%$ for veterinary and human medicine products safety), i.e. testing of substances and products to comply with legal regulations stipulated by government authorities, and animal-based research for the development of industrial products (31\% of all animal use; European Commission, 2007). Table 1 summarises the size of the respec-

Tab. 1: Industry size, number of new substances and animal use by industry sector

\begin{tabular}{|c|c|c|c|c|}
\hline & $\begin{array}{l}\text { Total EU industry } \\
\text { sale (b€) }\end{array}$ & $\%$ world market & New substances per year & $\begin{array}{c}\text { Animal use in } 2005 \\
\text { (number, \% of all animals) }\end{array}$ \\
\hline Pharmaceuticals & 484 & $28 \%$ & 12 & $6,090,000(50 \%)$ \\
\hline • toxicology & & & & • $490,000(4 \%)$ \\
\hline - vaccines & $\cdot 8.6$ & $\cdot 89 \%$ & $\cdot 1$ & $\cdot 1,850,000(15 \%)$ \\
\hline$\cdot R \& D$ & & & & • 3,750,000 (31\%) \\
\hline Cosmetics & 63 & $50 \%$ & $400^{*}$ & $5,600 *(0.05 \%)$ \\
\hline Food & 600 & $29 \%$ & n.a. & $500,000 \#(4 \%)$ \\
\hline - additives & $\cdot 5$ & $\cdot 29 \%$ & $\cdot 10$ & $\cdot 37,000(0.3 \%)$ \\
\hline Chemicals & 563 & $35 \%$ & 300 & $90,000(0.7 \%)$ \\
\hline Plant protection products & 8.6 & $27 \%$ & 8\# & $90,000(0.7 \%)$ \\
\hline
\end{tabular}

n.a. = not applicable; sources in text plus EU 2005 animal use statistics (European Commission, 2007).

* see (Hartung, 2008b) for estimate on new substances, which are mainly food ingredients and chemicals already tested for other purposes or

by supplying industry; \# see (Hartung and Koeter, 2008) for estimate of animal numbers (mainly shellfish toxin testing) 
tive industries in Europe and their share of the world market, estimated numbers of new substances introduced on the market per year as well as animal use numbers.

\subsection{Pharmaceuticals}

Finding new medicines for human disease and ensuring their safety for man is certainly the area in which animal use is best justifiable. In line, medical research uses a large part of all experimental animals, i.e. about 50\%. This corresponds with the enormous size of this world market: OECD Health Data (2005) totals spending on pharmaceuticals at $1-2 \%$ of the gross domestic product (GDP), representing $10-20 \%$ of health care costs in industrialised countries. Global pharmaceutical revenues are expected to surpass $547 \mathrm{~b}^{1}$ in 2009 (the US market had the largest share with 191-198 b€ in 2008 according to IMS Health (http://www.imshealth.com/)).

In Europe, EFPIA (European Federation of Pharmaceutical Industries and Associations, http://www.efpia.org/) represents 2,200 companies with 196 b€ retail sales on the world market. Eight of the top-20 companies (largest world-wide: Pfizer $>>$ Glaxo-Smith-Kline $>$ Sanofi-Aventis = Novartis, http://www. researchwikis.com/) are located in the EU.

Tens of thousands of pharmaceutical substances and preparations are in use, however, these prompt little further animal testing. Only astonishingly few new, original substances enter the world market every year: on average 10 to 15 ; IMS Health counted 57 new substances from 2000-2004 in the EU and 70 in the US. This represents a considerable slow-down compared to the nineties, where new substances in the EU totalled 89 from 1995-1999; and 88 from 1990-1994. This is remarkable in a number of respects:

a) It shows that many substances are entering the US but not the European market. This is certainly in first place due to the size of this market (world sales of pharmaceuticals 2006: 54\% North and South America, 28\% Europe, 19\% Asia, http:// www.researchwikis.com/), but to understand why after all the efforts spent companies decide not to market a new product world-wide, we need to understand that this is mainly due to the significantly higher sales prices for new products in the US and the risk of market pressures forcing lower prices there if cheaper markets are being served elsewhere. The US alone makes up $46 \%$ of world sales (EU: $31 \%$ ), but, more importantly, the US is responsible for $65 \%$ of sales of new medicines (EU: 24\%, Japan: 4\%) according to EFPIA. We will discuss the impact of the delayed introduction of innovative medicines at a later stage; Europe needs to stay alert here.

b) The evident decrease in substances making it to market is not due to lower R\&D spending (in Europe R\&D 26 b€, 107,000 scientists and in total 643,000 jobs, according to EFPIA). Part of the problem is the merging of major companies with subsequent reduction of the joint product pipeline. The main problem, however, is the so-called attrition rate, i.e. the number of substances failing in R\&D - IMS Health counts
7,322 substances in active R\&D (2005), remarkably higher than the number finally arriving on the market. A considerable number (8-30\%) of drug candidates fail because of safety problems in humans (Kola and Landis, 2004) in the clinical phase of evaluation despite having passed the entire toxicological programme. Many of these are certainly minor hazards, like nausea or a transient increase in liver enzymes, but we also do not assess the major chronic effects at this stage. Novel agent discovery strategies such as high-through-put screening or computer-aided drug design have obviously not impacted here in a positive way. It must be discussed to which extent precautionary animal testing impacts on these numbers (see below), i.e. that the considerably large proportion of false-positive results gained in some notorious animal tests sacrifices too many substances at rather late (expensive) stages of development.

c) The small number of new pharmaceuticals introduced to market carries enormous costs of on average $1.059 \mathrm{~b} €$ to develop one drug within typically 10-13 years. 1 in 5-10,000 tested substances is marketed ( 250 go to preclinical development; 10 continue to clinical development). Only 3 out of 10 marketed substances bring in enough revenue to surpass their development costs. 26 b $€$ are spent for drug R\&D in the EU (2007). This situation is increasingly unhealthy: Too many diseases are awaiting (better) therapies for us to afford such an inefficient machinery. Of course, the majority of the money is spent on clinical research, but animal tests make their contribution, both with regard to costs and time to market and, more importantly, when wrong decisions on the efficacy and safety of lead substances are taken based on the animal tests performed in the R\&D process. A critical reassessment of this too often unquestioned building block of the R\&D strategy is more than timely.

d)A large part of the difference between the number of new substances introduced in the EU and US in made up by biopharmaceuticals (today these are mostly recombinant human proteins and humanised antibodies): 1,600 EU companies with 33,000 employees investing 3 b€ in R\&D make 9 b€ revenue; 1,500 US companies with 146,000 employees investing 18 b€ in R\&D make 44 b $€$ revenue (EFPIA citing Ernst \& Young, 2007). With about half of the newly marketed substances being biopharmaceuticals, these actually represent the strongest incentive for moving away from animal testing, since a human protein cannot reasonably be tested in animals, as argued elsewhere (Hartung, 2008a; Hartung, 2009).

e) The situation is reversed for vaccines, where the EU harbours $89 \%$ of world vaccine production (2006) worth $9.7 \mathrm{~b} €$, but the US represents $50 \%$ of the sales market (EU: $32 \%$ ). Notably, vaccines are (at least with regard to the traditional products, i.e. live, attenuated, whole cell/virus and toxoid vaccines) most demanding with regard to animal testing: these products often still require continuous efficacy and safety testing in animals, accounting for $15.3 \%$ of all animal use in Europe 2005. Different from synthetic chemicals or gene technology-

\footnotetext{
${ }^{1}$ Financial figures are given in $€$ or million / billion $€(\mathrm{~m} € / \mathrm{b} €)$, using a conversion rate of 1.5 to the US $\$$ where necessary.
} 
derived vaccines, these products may differ between lots and require not only a package of animal data for the initial registration but regular tests, which belong to the most severe animal tests performed routinely.

\subsection{Cosmetics}

We addressed this area in an earlier article of this series (Hartung, 2008b) and included details on the cosmetics market there. The European trade association COLIPA (The European Cosmetic Association, http://www.colipa.eu/) totals annual EU sales at 58 b€ with a $4 \%$ growth rate. The EU Directorate General (DG) Enterprise quotes somewhat higher sales of cosmetic products (in 2006) at $€ 63$ billion, almost half the global total (http://ec.europa.eu/enterprise/e_i/news/article_6940_en.htm).

Five billion cosmetic items are sold per year in the EU by 2,000 companies, with 150,000 employees plus 350,000 employees in the respective retail business. The world market is estimated by others (http://www.researchwikis.com/) to rise to 300 b€ (2010), with a strong growth rate of $4-7 \%$ in the US. The largest companies are L'Oréal $(14 \mathrm{~b} €)>>$ Avon $(5.3 \mathrm{~b} €)>$ Estée Lauder (4 b€).

The market is extremely different from the pharmaceutical market: More than 20,000 new products with an estimated 400 new substances enter the market world-wide every year. About 15,000 substances are used in cosmetics products, as can be deduced from the list of "ingredient names" (The European Commission has recently launched "CosIng" http://ec.europa. eu/enterprise/cosmetics/cosing/, an online database of the ingredients used in cosmetic products). The finished products have extremely short shelf-lives, with $25 \%$ of turnover made with products that have been on the market for less than 6 months.

\subsection{Food}

Again we refer the reader to an earlier article in this series (Hartung and Koeter, 2008), which already gives some summaries, especially regarding the European food industry, complemented here by some US and global figures. Processed food sales worldwide add up to approximately 2.1 trillion $€$ (2004). In the US, consumers spend approximately $670 \mathrm{~b} €$ annually on food, (Plunkett Research, 2007) or nearly 10 percent of GDP. More than 16.5 million people are employed in the food industry (including retail and restaurants) (http://en.wikipedia.org/wiki/ Food_industry). $50 \%$ of top-50 companies are based in the US (http://www.researchwikis.com/), the biggest being Unilever and Kraft. The sector represents one sixth of US industrial activities with 1.5 million direct employees (2002).

The CIAA (Confederation of the food and drink industries of the EU, http://www.ciaa.be) totals the EU market in 2002 at 600 b€. The EU DG Enterprise on food industry (CIAA meeting, July 2008) pointed to the strong role of small/medium enterprises (SMEs, less than 250 employees) in the food sector (99\% of all enterprises, 70 to $80 \%$ of wholesaling companies are SMEs with $<5$ employees, around $50 \%$ of turnover, $62 \%$ of workers). On the same occasion H. G. Aleman (FIAB, the Spanish Food and Drinks Federation) estimated the number of European companies at 309,700 companies (cited source: CIAA data $\&$ TRENDS, 2007) with a total turnover of $870 \mathrm{~b} €$. The top-15 EU retailers record a turnover of 532.7 b $€$ per year (source: CIAA citing Veraart Research, 2006).

Regarding animal testing, the approximately 5,000 food additives used, with global sales of 16.9 b€ (2007), are most relevant, and Kraft is the largest individual company. The market for food additives in Western Europe, estimated at $3.3 \mathrm{~b} € /$ year, grows on average by $4.3 \%$ per year (Chemical Week Article, 1 st March 2000). Notably, in China 1,500 companies produce 3.25 million tons of food additives for the global market every year. However, as discussed previously (Hartung and Koeter, 2008), the introduction of new food additives is rather rare; only about 10 substances per year.

\subsection{Chemicals}

The European trade association CEFIC (European Chemical Industry Council, http://www.cefic.be/) estimates the chemicals world market at 1.6 trillion $€$ (Europe 563 b€, EU-25² 467 b€, NAFTA, i.e. North American Free Trade Agreement including United States, Canada, and Mexico, $417 \mathrm{~b} €$ ). 10 of the top-20 companies are based in the EU (BASF $>$ Dow $=$ Exxon $>$ Bayer $=$ Shell $=$ INEOS $>$ Sinopec $=$ Dupont $=$ Total $)$. This sector of European industry has 1.2 million employees, one third in 26,000 SMEs. Remarkably, 38 b€ trade surplus (2005) of this industry represents one quarter of all EU trade surplus.

The figures characterising this industry have often been presented in the context of the REACH legislation (Hartung, 2009): 27,000 European companies, an estimated 140,000 commercial chemicals, a little more than 100,000 registered as existing chemicals before September 1981, 30,000 of these estimated to fall under the $2006 \mathrm{REACH}$ legislation with a production or sales volume of more than one tonne per year. The entry of new chemicals into the market (so far with a threshold of $100 \mathrm{~kg}$ production/sale) over the last few years was about 200-300 per year (or about 5,000 since 1981).

General chemicals are produced by 8,530 enterprises in the EU-27 in 2005, employing 574,000 people and producing an added value of 64 b€ (Eurostat, 2008).

The area of chemicals is dominated by the REACH (Registration, Evaluation, Authorisation and Restriction of Chemicals) legislation (European Commission, 2006), the consequences of which are difficult to predict, both with regard to animal testing requirements and forced exchange of substances. The latter may be prompted by the foreseen restriction and authorisation of substances newly identified as harmful, as well as by changes of use of chemicals based on findings not requiring these more drastic regulatory measures. Not to forget, many substances might be abandoned by their producers to avoid the testing and registration effort for low profit substances.

2 EU-25 refers to the 25 member states of the EU as of 1st May 2004, while EU-15 is used to describe the

$\mathrm{EU}$ of the "old" 15 member states and EU-27 the EU after the enlargement of 1st January 2007. 
This will prompt innovation, but will likely also increase the number of new chemicals entering the market in the medium term.

\subsection{Plant protection products}

The world market of 2004 for plant protection products (PPP) was estimated at $32.5 \mathrm{~b} €(\mathrm{http} / / / \mathrm{www} . r e s e a r c h w i k i s . c o m /)$ with 45\% pesticides, $28 \%$ insecticides and 22\% fungicides. Mostly chemical companies also sell PPP: BASF (11\% of their sales), Bayer (20\%), Dow (9\%), Dupont (16\%). It takes an average of ten years and an investment of about $200 \mathrm{~m} €$ to develop and register a new pesticide.

In the EU (From farm to fork statistics, Eurostat, 2006), 353,000 tonnes of PPP (1999, EU-15) worth 8.6 b€ (2003, EU25) compared to 15.6 million tons of fertiliser (1999, EU-15) worth 10.7 b€ (2003, EU-25) were sold. Most recent sales in the EU (2007 according to European Crop Protection Association, http://www.ecpa.be/) totalled $7 \mathrm{~b} €$ with roughly $3 \mathrm{~b} €$ each for herbicides and fungicides as well as $1 \mathrm{~b} €$ for insecticides (annual report 2007-2008, http://www.ecpa.eu/website/page. asp?cust $=3 \&$ lang $=e n \& m i=4)$. The volume of products used in the EU-15 increased from 2002 to 2007 by $73.4 \%$ up to 270,714 tonnes (due in particular to a $12 \%$ increase in herbicide volumes). In the EU-15 and Switzerland, staff numbers stand at a total of nearly 23,800 employees.

The number of PPP is estimated to be around 1,000 with only about 8 new substances (but many more formulations of established substances) entering the world market per year. European Union legislation (Directive 91/414/EEC) has already resulted in a reduction of the available portfolio of pesticides in Europe by more than $55 \%$ over the last decade (530 of the 952 crop protection products that existed previously have been eliminated). Some scientist fear that from a resistance management point of view, the crop protection products portfolio in Europe has already been very seriously impaired by the ongoing EU re-registration process (http://www.irac-online.org/documents/ ljubljana_pressrelease.pdf). A further significant reduction in compounds is to be expected from the current revision process of Directive 91/414/EEC. This will likely result in increased needs for new substances and might impact on R\&D in this field in the medium term.

A key difference to other chemical products is that PPP need to be toxic. While biological activity is otherwise only desired for pharmaceuticals, this implies that toxicity also to man is much more of a concern for PPP. Something that is for example toxic to insects has a certain likelihood of being toxic to humans. The World Health Organisation and the UN Environment Program estimated that each year 3 million workers in agriculture in the developing world experience severe poisoning from pesticides, about 18,000 of whom die (Wikipedia citing Miller GT (2004), Sustaining the Earth, 6th edition. Thompson Learning, Inc. Pacific Grove, California. Chapter 9, Pages 211-216). As many as 25 million workers in developing countries may suffer mild pesticide poisoning yearly (Jeyaratnam, 1990). But these estimates are rather old and do not stand up to all criticism. More recently (Lichfield, 2005), it was concluded that pesticide poisonings only make up a small proportion $(<1-4 \%)$ of the several million cases of occupational injuries and ill health in agricultural workers worldwide. This still prompts very extensive data requirements for the toxicity evaluation of PPP: EPA states that on average a toxicity package worth 19 million US $\$$ is available for each of the 900 registered PPP. This is a wealth of information increasingly exploited for the development and evaluation of novel approaches, e.g. in the US EPA ToxCast programme (http://www.epa.gov/ncct/toxcast/index.html).

\subsection{Geographical spread}

Different economic areas compete with their regulations by imposing their standards on their trade partners. Trade volumes are thus of key interest, as already discussed for pharmaceuticals, where the predominance of the US sales market for new medicines makes FDA standards dominant in pharmaceutical industry. However, general trade, e.g. household products, cosmetics, food or chemicals, is much more dominated by Europe. For example, while Europe imports about $50 \%$ of its food, the US produces $90 \%$ nationally. World trade reflects the strong role of Europe as shown in the global figures in b€ (Le Monde diplomatique, 2006): Europe (2687 b€) $>$ Asia (1592 b€) $>$ North America ( 883 b€) $>$ Gulf States (260 b€), South America (184 b€), Russia/Eastern Europe (177 b€), Africa (155 b€). This means that Europe has a share of $45 \%$ of the world trade. We have seen that its share of regulated industries of the world market, however, is around $28 \%$, with the notable exceptions of vaccines $(89 \%)$, cosmetics $(50 \%)$ and chemicals (35\%), the latter claiming to contribute one fourth to the trade surplus of the EU. For cosmetics, with the biggest EU states' markets maturing, EU companies are increasingly turning to exports. EU exports of cosmetic products have grown strongly in recent years. The trade balance is firmly in the EU's favour, with exports almost four times the value of imports. The big EUbased companies make almost one-third of their sales on foreign markets, and SMEs also export 10 to $20 \%$ of their production to non-EU countries.

It is obvious that Europe has a strong interest in harmonising regulation and easing international trade. Here it is remarkable that exactly those industries that contribute most to world trade surplus are now being forced to introduce alternative approaches to animal testing (by the $7^{\text {th }}$ amendment of the cosmetics directive and by REACH). This dominance on the world market will have strong implications for spreading these novel approaches to other economic areas, as discussed later.

\section{Consideration 2: Animal testing is a market, and a global industry leads to global animal use}

Taylor and co-workers recently performed a very interesting analysis of animal use in different countries (Taylor et al., 2008). When plotting their estimates per country against GDP, i. e. the most common measure of national income and output for a given country's economy (GDP = consumption + gross investment + government spending + (exports - imports)), we see 


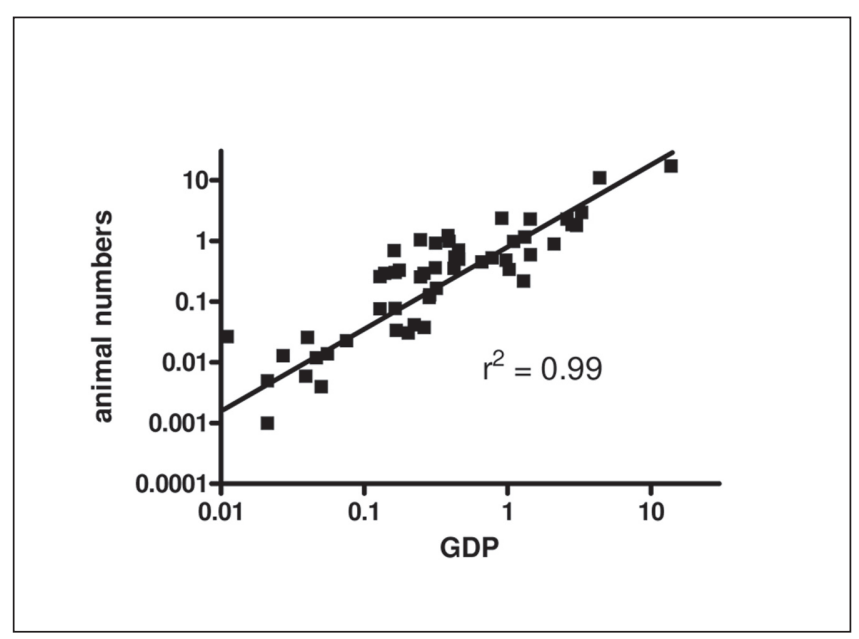

Fig. 1: Correlation of GDP with animal use

Correlation of gross domestic product (GDP) in trillion US\$ for 52 countries (Wikipedia, 2008) in 2007 for members of the International Monetary Fund with animal use estimates (Taylor et al., 2008) in million animals per country. A linear regression analysis of the log-transformed data was carried out.
(Fig. 1) an almost perfect correlation $\left(r^{2}=0.99\right)$. The message is simple: economy needs animals - almost exactly one animal per million \$ GDP - and there are no major deviations for the major economies. Europe has about $30 \%$ of world GDP, and we can use this to translate the European data to other economies.

What does regulatory safety testing of synthetic substances cost? Fleischer (2007) carried out a survey on costs and capacities of laboratories running safety assessments in 9 countries. Since this is a competitive market with a stable situation of demand and offer of test capacities (which might change soon in the context of REACH, see below), the average prices can be used as a solid estimate of test costs, also for in-house tests in some companies. Applying these costs and the animal numbers per test to the EU statistics on animal use in 2005 results in an estimation of the testing costs (Tab. 2): This rough estimate suggests that toxicity and safety assessments in Europe cost $620 \mathrm{~m} €$ per year. This is based on several assumptions, e.g. that contract research laboratories (CRL) cost about the same as in-house testing, that the prices for Good Laboratory Practice (GLP) compliant testing used are not too different from non-GLP-studies (typically $20 \%$ additional costs are given as a sound estimate), and that studies grouped here under a certain heading reflect the costs of the respective guideline test. However, the overall result seems reasonable with regard to rank order when compar-

Tab. 2: Estimate of costs of toxicological testing and safety evaluations in Europe

\begin{tabular}{|c|c|c|c|c|}
\hline Animal test & Animal number per test & Costs per test [€] & Animal use in 2005 & Total cost $[k €]$ \\
\hline In vivo skin irritation & 2 & 650 & 12,243 & 3,978 \\
\hline In vivo eye irritation & 2.7 & 1,343 & 4,208 & 2,093 \\
\hline Skin sensitisation & 23 & 3,959 & 43,889 & 7,554 \\
\hline Further mutagenicity & 64 & 18,898 & 35,483 & 10,477 \\
\hline Acute oral tox & 8 & 1,474 & 237,110 & 43,687 \\
\hline Acute inhalation tox & 20 & 11,734 & 21,556 & 12,646 \\
\hline Acute dermal tox & 10 & 2,011 & 43,110 & 8,669 \\
\hline Short-term repeated dose & 50 & 49,390 & 129,333 & 127,755 \\
\hline Sub-chronic tox & 32 & 115,656 & 55,934 & 202,159 \\
\hline Long-term repeated tox & 160 & 372,000 & 55,934 & 130,047 \\
\hline Developmental tox screening & 560 & 54,597 & 8,099 & 789 \\
\hline Developmental tox study & 300 & 63,100 & 32,398 & 6,814 \\
\hline Two-generation reprotox & 3,200 & 327,975 & 63,311 & 6,489 \\
\hline Carcinogenicity & 400 & 780,357 & 42,024 & 81,984 \\
\hline Short-term fish & 42 & 4,193 & 11,408 & 1,139 \\
\hline Long-term fish tox & 108 & 9,319 & 634 & 54 \\
\hline BioAccumulation (fish) & 70 & 40,330 & 634 & 365 \\
\hline Total & & & $1,026,286$ & 619,699 \\
\hline
\end{tabular}

Animal use numbers for 2005 (European Commission, 2007) were interpreted by applying costs and animal numbers of guideline tests. Some tests are grouped in the 2005 animal use statistics; the following rough assumptions were used to split these: acute and subacute tests (Acute oral tox $55 \%$, Acute inhalation tox $5 \%$, Acute dermal tox $10 \%$, Short-term repeated dose 30\%); subchronic and chronic tests (Sub-chronic tox 50\%, Long-term repeated tox $50 \%$ ), developmental toxicity (Developmental Tox screening 20\%, Developmental Tox study $80 \%$ ) and toxicity to aquatic vertebrates (Short-term fish $80 \%$, Longterm fish tox $5 \%$ and BioAccumulation (fish) $5 \%$ ). 
ing them to the turnover of CRL calculated below. Interestingly, this estimate would suggest that most resources are spent on (sub-)chronic testing (332 $\mathrm{m} €$ ), (sub-)acute testing (127 m€) and carcinogenicity testing $(82 \mathrm{~m} €$ ). Extrapolating these data to a global scale, a multiplication factor of 3-4 based on overall animal numbers and share of world market of industries seems realistic, suggesting that $2-2.5 \mathrm{~b} €$ are spent for toxicological testing per year worldwide.

It is difficult to find an estimation of the number of people working in animal testing. A report (Lantra, 2006) acknowledging the "sensitive nature" of this information estimates 285 businesses with 3,400 people in the UK. The latter number is substantiated by about 2,200 members of the key organisation, the Institute of Animal Technology. Their organisational breakdown is: government organisations $(10 \%)$, research council $(6 \%)$, medical research $(17 \%)$, commercial breeder $(3 \%)$, university $(32 \%)$, commercial pharmaceutical company (16\%) and other $(15 \%)$.

According to the Lantra report, 14,000 personal license holders for animal experimentation (i.e. mainly scientists) carried out experiments on 2.72 million animals in 2003. There is no reason to assume that in other countries significantly less or more personnel are required for conducting animal experimentation. Thus, more than 60,000 people might be involved in animal testing in Europe, or about 300,000 worldwide, based on the estimates of Taylor et al. (2008). Similarly, the 3,400 professionals working in the UK on animals for experimental purposes can be extrapolated to 14,600 in the EU and 73,000 world-wide.

An important part of the animal testing market is made up by CRLs. A comparison of top competitors (2007 sales revenue and market share) is given by Wikinvest (http://www.wikinvest. com/stock/Charles_River_Laboratories_International_(CRL)): Covance 1.167 b€ (28.5\%), Charles River Labs $757 \mathrm{~m} €$ (8.5\%), MPI Research 75 m€ (1.84\%), Harlan Sprague Dawley 34 m€ $(0.83 \%)$, Huntingdon Life Sciences Research $15 \mathrm{~m} €(0.36 \%)$ and others (privately owned) with an estimated 50\% market share. Thus, this represents an industry with 4.1 b€ total sales.

In conclusion, animal experimentation represents a relevant industrial branch in its own right.

\section{Consideration 3: The extent of animal test based regulation differs between industrial sectors}

In the then 25 member states of the EU (EU-25), 12.1 million animals were used in experiments in 2005 (European Commission, 2007). Considering only the EU-15, the total number of animals used had increased in 2005 by 339,279 compared to the previous report from 2002, representing an increase of $3.1 \%$. The number of animals used for toxicological and other safety evaluations has dropped from about 9.9\% (data of 2002) to $8 \%$ of all animal use in Europe in 2005. But in total numbers, the decrease is only minor, i.e. from $1,066,047$ to $1,026,286$ animals.

Table 3 compares the different industries with regard to the extent of animal use for regulation of the sector, also based on the regulatory testing per new substance or per $b €$ of turnover of the industrial sector (Tab. 2). Clearly, the search for new drugs consumes the most animals, obviously owing to the many substances tested but abandoned on the way. Chemicals require little testing, most of them receive just the basic set ("six-pack": skin and eye irritation, skin corrosion, mutagenicity, sensitisation, acute toxicity testing) of testing. Food additives and PPP consume considerably more animals, both because of higher testing demands and for substances never making it to the market.

\section{Consideration 4: Recent European legislation for cosmetics and chemicals changes the business of animal tests and alternative methods}

In recent years, Europe has taken over the role of global pacemaker for consumer and environmental protection legislation from the US. The respective legislation that uses animal tests for implementation and regulation (especially $\mathrm{REACH}$, the $7^{\text {th }}$ amendment of the cosmetics regulation, the general food legislation, several revisions for food additives and genetically modified food and feed, as well as the current revision of the PPP directive) deserves some thoughts here.

Tab. 3: Regulatory animal testing relative to the introduction of new substances or annual turnover in Europe

\begin{tabular}{lcc} 
Sector & Animals / new substance & Animals / b€ turnover \\
\hline Pharmaceuticals & 41,000 (including R\&D 353,000) & 4,800 \\
\hline Cosmetics & n.a. & 89 \\
\hline Food additives & 3,700 & 7,400 (all food 833) \\
\hline Chemicals & 300 & 159 \\
\hline PPP & 11,300 & 10,465 \\
\hline
\end{tabular}

Data in Table 1 on EU animal use are given relative to the number of new substances introduced per year or the EU revenues in this sector. For pharmaceuticals both figures based on regulatory tests only and in brackets those including animal use for agent discovery are given. For cosmetics, which use new substances tested for other purposes or by other industries, numbers are not applicable (n.a.). Since animal testing for food is mainly for food additives (with the most important exception of shellfish control not falling into the categories of this table), data are restricted to this field, but the proportion relative to all food turnover is given in brackets. 


\subsection{The REACH effort}

The Registration, Evaluation, Authorisation and Restriction of Chemicals (REACH) legislation is the largest investment into consumer safety ever. REACH has been described extensively elsewhere (http://echa.europa.eu/home_en.asp, http://ecb.jrc. ec.europa.eu/reach/). It is an unprecedented effort and will have percussions on the global chemical industry. Notably, there are efforts both in Japan and California to set up similar approaches. The US HPV (high production volume) chemical programme is not comparable with regard to the number of chemicals $(4,000)$ and data requirements (most are dealt with by read-across, (Q) SAR (quantitative structure activity relationship), and existing data) as well as the voluntary nature of the programme.

The first interesting aspect is the cost of this programme. Fleischer (Fleischer, 2007) has calculated the average price of the test packages for REACH according to tonnage levels. Combining this information with the estimates of substances falling into the different tonnage categories, results in the figures in Table 4.

This means that data worth almost 9 b€ will be collected. How much of this data is already available, how new testing strategies might impact on the costs, how many substances will be abandoned, and whether the estimates on substance numbers are correct, are questions that deserve a separate, in-depth analysis. The best analysis so far dates back to 2004 (Pedersen et al., 2003). That analysis does not sum up the testing costs generated if all tests really have to be carried out from scratch, but examines different scenarios which suggest about 1.6 b€ (maximum $2.4 \mathrm{~b} €$ ) of direct testing costs, based on extremely optimistic assumptions about available data, waiving of testing and acceptance of (Q)SAR analysis. For example, the authors assume that only $7.3 \%$ of the two-generation reproductive toxicity studies (which in most scenarios account for $>50 \%$ of the costs and $>70 \%$ of the animal use of REACH) will have to be carried out, although the test guidelines published by the agency and analyses on data availability (Bremer et al., 2007) give no indication that test omissions will be possible. Noteworthy, the figure of $1.6 \mathrm{~b} €$ does not include the cost of administering the registrations within the companies, the registration fees of the agency, additional testing to challenge/verify results, costs for substitution of substances, etc. It is fair to assume that all these contributions will significantly increase the overall costs. The higher figures are corroborated by estimates made by BASF (personal communications around 2005), where about 2,700 substances falling under REACH are expected to produce additional costs of $600 \mathrm{~m} €$ (and require about 150 additional personnel). Noteworthy, already in 2001 the MRC in Leicester (MRC-IEH, 2001) calculated 8.7 b€ of costs and 50 million animals. They identified a lack of testing facilities, finding only 16 suitable CRL in Europe and also warned that the actual number of substances requiring testing might be as high as 65,000. In fact, ECHA has published a list of pre-registered substances on its website (http://echa.europa.eu/news/press_en.asp): The list contains about 150,000 substances which were pre-registered by 65,000 companies between 1 June and 1 December 2008 . Thus, all estimates on costs and animal numbers will need to be updated once this list has been reviewed.

REACH plans for the last preliminary safety assessments to be submitted in 2019. Since the lowest tonnage levels do not require authorisation of proposed animal experiments, this would theoretically mean that the work on the existing chemicals should be completed about two years later. Thus, over the next decade, on average more than one $b €$ of costs per year will be imposed on the chemical industry. This might be considered insubstantial given the $600 \mathrm{~b} €$ annual turnover of this industry in Europe, but profit margins are generally considered to be narrow and competition, especially for large-volume chemicals, is fierce, especially with some Asian producers.

Test capacity is a big issue. What total capacity is available today, which part can be used by chemical industry and which capacities can be created? Let us attempt a naive estimation: Today, about 300 new substances are handled per year. REACH will require roughly 3,000 substances to be tested every year; thus, the testing capacity for chemicals needs to be increased ten-fold. Since testing of chemicals makes up $10 \%$ of all animal use for toxicology (and toxicology 10\% of all animal use), this roughly means doubling toxicological testing capacity. However, this calculation immediately falls short, because the nature of tests required will change dramatically: Almost all new chemicals so far fall under tonnage levels between $100 \mathrm{~kg}$ and 10 tonnes, with rather limited information requirements. In contrast, the most relevant testing demands for REACH originate from a completely different set of information requirements, i.e. reproductive and chronic toxicity testing. The most dramatic example is the most animal demanding test (two-generation reproductive toxicity testing with 3,200 animals per substance) - over the last 26 years about 3 chemical substances per year required such tests. REACH is expected

Tab. 4: The value of information requirements in REACH

\begin{tabular}{cccc} 
Tonnage level & Expected number of substances & Average cost for full test set [€] & Total costs [billion $€$ ] \\
\hline $1-10 \mathrm{t} / \mathrm{a}$ & 20,000 & 279,360 \\
\hline $10-100 \mathrm{t} / \mathrm{a}$ & 4,600 & 7.13 \\
\hline $100-1000 \mathrm{t} / \mathrm{a}$ & 2,900 & 2.32 \\
\hline$>1.000 \mathrm{t} / \mathrm{a}$ & 2,600 & $1,582,616$ \\
\hline Total & 30,100 & & 8.12 \\
\hline
\end{tabular}


to require about 5,500 such tests (Höfer et al., 2004) in total, or more than 50 per year.

If we assume that the costs estimated by Fleischer for the 1-10 tonne package reflect current average testing demands for new chemicals, annual testing costs of $16.9 \mathrm{~m} €$ result, while REACH will require about $880 \mathrm{~m} €$, a 52 -fold increase (assuming that test costs reflect the use of capacities and resources of the laboratories, which should be so in a competitive market where the animals themselves are a minor cost factor). Since there will be peaks in testing demands, this figure might be even larger in some years.

Outsourcing of animal testing to countries like India and China represents an important consideration here. This is possible in principle, if the requested quality standards (Good Laboratory Practice, GLP) are met. At this moment, the lack of accreditation and inclusion of these countries into the respective OECD processes largely prohibits such outsourcing, but this might change soon. This will lead to changes in costs and will impact on the animal numbers used in Europe (though not on the global total). The extent of such lateral shifts that will occur between geographical regions is not clear. From an animal welfare point of view, this is clearly not desirable, i.e. exporting testing to countries with lower animal welfare standards. An interesting amendment to REACH could be to request data obtained for submission to adhere to European animal welfare standards independent of the country in which the tests were performed.

\subsection{The $7^{\text {th }}$ amendment of the cosmetics directive}

Some key aspects have been discussed in an earlier part of this series (Hartung, 2008b). Some remarkable features of this legislation are:

- the request for alternative methods, reinforced by deadlines even in the absence of (accepted) alternatives - with bans starting in 2009 and 2013 on the marketing of products containing substances tested on animals in Europe; it is very unusual that an industry is expected to develop the tests for their regulation itself and to reinforce this with a marketing ban although no danger to consumers etc. is expected.

- the global outreach - according to current interpretation, the ban extends to tests carried out outside of Europe (even when required there by law).

- the lack of regulatory implementation - it is not clear who will control and prosecute (reinforce the marketing ban).

- the lack of prosecution so far - already since September 2004 the directive bans the marketing of products if ingredients have been tested on animals although alternatives have been accepted or if finished products have been tested on animals. We are not aware of any compliance check, but products have obviously been put on the European and in parallel onto other markets that require end-product testing since this deadline.

\section{Consideration 5: Animal testing serves different functions in the product life cycle}

\subsection{Agent discovery}

This refers mainly to biologically active agents, i.e. drugs and PPP. Animal testing has lost a lot of its importance for agent discovery: Search strategies with higher through-put are typically being employed - logical given the figures on the number of substances that must be tested to identify a lead compound. The overall reduction of animal use by probably two thirds over the last three decades mainly reflects this change (beside the reduction of duplicate testing). Today, a molecular understanding of the pathophysiology and the desired mode of action generally allow the use of non-animal methods, with late stage confirmatory testing in a disease model in case of drug development.

\subsection{Safety assessments and liability}

Safety evaluations are typically defined by regulatory requirements. This is certainly telling: Shouldn't every product have a certain profile of reasonable test requirements, which address for example the "excess pharmacology" of the agent and chemical class specific concerns? Shouldn't the company spending a billion $€$ on the development of a drug know it very well and be able to choose the right set of tests? Instead, a tick-box approach is followed and only a standard list of tests is run. This has several advantages for both the notifier and the regulator:

- A standard set of information means few difficulties in interpretation (comfort zone of the regulator).

- Omitting a certain test might imply responsibility if effects are found later.

- The production of the dataset can be timed easily because a standard battery is run.

- Defence against liability claims is easy since the state of the art has been applied.

However, animal use might be considerably reduced if information requirements had to be justified towards the regulator and liability stayed with the producer. REACH is moving into this direction by requesting a test plan to be approved by the agency for higher tonnage level chemicals and shifting the burden of proof (liability) to the industry. It will be interesting to see whether this new approach works out and can be transferred to other sectors.

\subsection{Marketing with "animal welfare"}

The success of The Body Shop with their aggressive "Against animal testing" strategy is the key example here (http:// en.wikipedia.org/wiki/The_Body_Shop): Signage posted in The Body Shop locations reads, "Our products are not tested on animals, never have been and never will be." However, the Body Shop website expands this to acknowledge that "the fact is that almost all cosmetics ingredients have been animal tested by somebody at some time for someone. So no cosmetics company can claim that its ingredients have never been animal tested." It is not clear what the actual value of this statement is (http://www.mcspotlight.org/beyond/companies/bodyshop. 
html): According to market leader L'Oréal no cosmetic product has been tested on animals in Europe since 1989, but all (most probably including those sold in The Body Shop) make use of ingredients tested on animals by others, especially the supply industry. However, it represents a model for a marketing strategy which has put competitors under pressure. The Body Shop experienced rapid growth (expanding at $50 \%$ per year). The success of the brand (which is since 2006 part of L'Oréal) demonstrates the value put on animal welfare by consumers, in line with results of recent European surveys showing an extremely high importance given by citizens to animal welfare issues (A 2005 EUROBAROMETER survey recorded that $82 \%$ of EU citizens believe we have a duty "to protect the rights of animals whatever the cost". A 2006 EU Commission survey showed that $93 \%$ of respondents believe more needs to be done to improve the welfare/protection of experimental animals). It might be appropriate to think about a protected "not tested on animals" label with the respective standards.

\subsection{Trade barriers}

Different safety testing standards are barriers to free trade. We have earlier discussed the important role of OECD test guidelines in harmonising test requirements (Bottini et al., 2007). However, we must not forget that there are important markets outside the OECD. Countries like Brasil, China and Russia, to name only some, represent not only exporters but, with an increasing upper class and high-tech industry, also importers of European products. Thus their reliance on traditional methods is an obstacle to the introduction of any novel approach - even if accepted in the OECD. The only possible solution is the insistence on the novel method (e.g. by deleting the traditional one from the catalogue of test guidelines as done so far only for the classic $\mathrm{LD}_{50}$ test, OECD TG 400) and the international collaboration and harmonisation with all major (emerging) markets. Since we represent far more interesting export markets for them, chances are that we may also be able to export our standards to them (see below).

\section{Consideration 6: Alternative methods are a market in their own right}

We have shown earlier that animal testing is a multi-b€ market - alternatives have the potential to take over this market. In fact, some alternative methods, such as pregnancy tests or pyrogenicity testing (Limulus test), have reached three-digit $m €$ sales. Especially REACH raises hopes that certain novel methodologies will find a market, which will smooth their standardisation and commercialisation. This improves their availability and international use. To some extent, the market of alternative methods is also expanding owing to the silent substitution of services by contract research laboratories (mutagenicity, skin and eye corrosion/irritation, fish egg test etc.). Still, development, validation and regulatory acceptance take too long (more than 10 years) to suit the needs of biotech companies for return of investment. There is room for improvement.

\section{Consideration 7: The limitations of animal tests have economic consequences}

Using a technology with limitations comes at a price. There are mechanisms at work to cross out the limitations and their price. In the following we shall make some estimates of the latter.

\subsection{Black swans}

We have discussed the impact of prevalence on toxicity testing earlier (Hoffmann and Hartung, 2005). The concept is easy: when looking for a hazard, we need to consider whether it is a frequent or a rare one. If it is frequent, even methods with a large uncertainty will do well. But if we are looking for something rare, the error rate becomes relevant, even for reasonably good methods. To give an example, we typically accept an error rate of $5 \%$ in science (in statistical tests of significance). If we are looking for a hazard that is expected in $5 \%$ of the substances tested, we will end up with roughly as many correct positive as false-positive results. This means half of the substances tested that get a verdict of "guilty" are in fact innocent. If we go lower than $5 \%$ prevalence (which is more realistic), if we employ methods with larger limitations (which is more realistic) or when we apply precautionary approaches (which is what we typically do), we further worsen the equation, ending up with even more false-positive results.

This might be acceptable for new substances without an established economic value, but when REACH now applies the very same strategy to the most valuable substances in the chemical industry, the sacrifice might be more than substantial.

The concept has recently been put forward much more elegantly by Nassim N. Taleb in his wonderful book "The black swan" (Taleb, 2007). He defines black swan events by the "triplet: rarity, extreme impact and retrospective (though not prospective) predictability". Which toxicologist does not immediately think of thalidomide/Contergan ${ }^{\mathrm{TM}}$, Lipobay ${ }^{\mathrm{TM}}$ or Vi$\mathrm{oxx}^{\mathrm{TM}}$ ? Taleb claims "what is surprising is not the magnitude of our forecast errors, but our absence of awareness of it". In toxicology, we often take the absence of evidence of a hazard as evidence of its absence. This is when the black swan hurts. The compensatory mechanisms are precautionary methodologies; we presume higher frequencies of hazards to allow the application of Gaussian type statistics and reasoning. However, this only creates the belief that we have covered most of the putative hazards, and finding so many harmless or borderline events belittles the real threat. Taleb acknowledges an enormous problem: "True, our knowledge does grow, but it is threatened by greater increases in confidence, which makes our increase in knowledge at the same time an increase in confusion, ignorance, and conceit."

\subsection{Precautionary testing}

The precautionary principle goes back to the German concept of a "Vorsorge-Prinzip" (cautionary principle), although there is no generally accepted definition (Gollier and Treich, 2003; Lofstedt et al., 2002). In general, it means that in case of uncertainty 
a worst case scenario is assumed and decisions are taken on its basis. In toxicology, the concept is inherent in the creation of over-sensitive test models that minimise false-negatives (missed toxicants) by accepting false-positives (wrong allegations of toxicity). High doses, use of the most sensitive species, testing in several species and sensitive endpoints (low thresholds for toxicity categories) are the typical tools employed to render a test sensitive. This follows the same precautionary logic.

The precautionary principle has been disputed from various sides, e.g. the Wall Street Journal wrote in an editorial (Gollier and Treich, 2003): The precautionary principle "...is an environmentalist neologism, invoked to trump scientific evidence and move directly to banning things they don't like - biotech, wireless technology, hydrocarbon emissions". Stephen Breyer (1993, Breaking the vicious circle: toward effective regulation) has attributed the problem to "a public hungry for worst-case scenarios to inflame its fears, and to a class of risk assessors all too eager to fuel this fire". Such extreme criticism has been addressed (Resnik, 2003), and the conclusion reached, i.e. that the principle is scientific if threats are credible and the precautionary measures are reasonable, is consistent with an evidencebased approach to policy-making.

If taken too far, the precautionary principle may indeed inhibit economic development (Gollier and Treich, 2003). One key problem is the "opportunity cost of precautionary measures" (Majone, 2002): The attempt to control poorly understood, low-level risks necessarily uses up resources that in many cases could be directed more effectively towards the reduction of well-known, large-scale risks. But there is also a further type of opportunity cost to consider, i.e. abandoning a certain substance or restricting a technology impairs opportunities for business and to serve societal needs. An evident example is a therapy that does not make it to the market/patient because precautionary tests suggest a toxicity problem. It is difficult to estimate the danger posed from such a result. We have tried elsewhere to estimate the false-positive rate of prominent toxicity tests (Hartung, 2009): To identify the estimated 5\% carcinogenic chemicals, for example, the cancer bioassay is employed, which finds $53 \%$ of all substances positive; to identify $2-3 \%$ reproductive toxicants, the two-generation test in two species is employed, which finds about $60 \%$ of substances positive. If these were independent tests, they alone would together only let $19 \%$ of substances pass without assigning them a carcinogenic or reproductive toxicant label, a sure elimination from further development unless they are being developed as chemotherapy for cancer. But the toxicological toolbox is much larger...

Lichtenberg (Lichtenberg, 2005a) calculated the impact of the launch of new chemical entities (NCE), i.e. structurally new drugs, on the steady increase in human longevity: He used the IMS Health Drug Launch database, which has tracked product introductions worldwide since 1982 and contained 165,000 records in August 2001. From this he evaluated for each country and therapeutic area the actual number of ingredients launched. This was matched to the WHO Mortality database using 11 broad disease categories. He showed that launches of NCEs have a strong positive impact on the probability of survival. Between 1986 and 2000, the overall population gained 1.96 years of life expectancy and, according to these estimates, NCE launches account for $40 \%$ of these, i.e. 0.79 years. He calculated that the average annual increase in the world population age resulting from one NCE launch is 0.056 years (2.93 weeks). What impact might five times more substances moving ahead in clinical development have, if the false-positive results of the cancer bioassay and the two-generation reproductive toxicity study could be avoided?

Lichtenberg confirmed his data with a study of differences in drug launch times in the federal states of the US (Lichtenberg, 2007). Here he even found a $63 \%$ contribution to increase in life expectancy by new drugs (2.43 years from 1982 to 2004). In another study (Lichtenberg, 2005b), he showed the impact of changing from the prescription of old (pre-1970) to new drugs on mortality in 800,000 people of the Medicaid programme in the first half of 2000 . He calculated that the actual mortality rate of $3.5 \%$ for the following 2 years would have been $4.4 \%$ if all had received pre-1970 drugs.

This argument shows that a precautionary test approach resulting in an unnecessary reduction of drug candidates or pressure to change to lead compounds with a less favourable pharmacological profile directly affects society, not only the prosperity of the individual company. Similar calculations for other areas of regulation are not available, but we have been warned of the true costs of a precautionary chemicals regulation (Durodie, 2003).

\subsection{Technology mismatch}

The question we must address is: can products of the early $21^{\text {st }}$ century be regulated using methods of the early $20^{\text {th }}$ century. Sure, some things never change, because they are basic and meet the need, such as measuring length with a meter. But even this required numerous improvements on the definition of and international agreement on a "gold standard". The purpose of animal tests, however, is rather complex and changing, and we are far from international gold standards. The closest we have come are international test guidelines, with known and unknown limitations (Hartung, 2008a).

We have earlier commented on the problem of fixing these international guidelines in time (Bottini et al., 2007): it takes a decade to generate one, but currently it takes the same length of time to make any significant changes; at the same time, the range of regulated products is changing with an ever accelerated pace. Recent examples include cellular therapies, gene technologies, nanotechnologies. This turnover forces us to regularly review the way we do things, to allow the evolution of toxicology (Hartung and Leist, 2008; Leist et al., 2008). However, we lack a mechanism to drive this change. We might argue that the validation of alternative approaches is this mechanism, a means to introduce innovative methods to replace the old ones. The key problem, however, is that as long as we consider the status quo to be the gold standard without any limitations, we cannot really move ahead and improve. The best we can do is to achieve an approximation with a perceived compromise, because $100 \%$ identical results are usually not achieved. We have therefore proposed (Hoffmann and Hartung, 2006) a mechanism to systemat- 
ically review the status quo methodology on the basis of the best evidence available at a given time, using the most objective and transparent processes. Borrowing from the field of clinical medicine and their evidence-based medicine movement, the suggestion was put forward to create an evidence-based toxicology. It is remarkable that in less than three years, the idea has flourished with the proceedings of the first international forum held in 2007 being published (Griesinger et al., 2009; http://www. ebtox.org), a symposium being held at the last EuroTox in 2008, and a special issue on the topic being prepared in the journal "Toxicology". Furthermore, one of the authors (TH) was privileged to be appointed the first chair for evidence-based toxicology at the beginning of 2009 (Doerenkamp-Zbinden chair for evidence-based toxicology in the Bloomberg School of Public Health at Johns Hopkins University, Baltimore, US). Since this university also hosts the Cochrane center for evidence-based medicine for the US, an optimal synergy with the far more established EBM movement can be hoped for.

\section{Consideration 8: Economic forces could improve the situation}

The common European market was the driver for the progressive European animal welfare legislation. In principle the EU has no mandate for animal welfare. It is remarkable that the Directive $86 / 609 / \mathrm{EEC}$ on the welfare of laboratory animals was only created because it was deemed that different animal welfare standards made for unfair conditions for entering the common market in different Member States. In principal, the legislation does thus not cover basic research, but most Member States updated this in one act when translating it into national law.

But it is not only the political will and the forces of the common market which have helped to raise the importance of animal welfare. We see in general that ethical aspects of business are receiving increasing attention. Ethical treatment of employees, consideration of different cultures, marketing with ethical arguments and social responsibility are increasingly integral in the culture of individual companies.

\subsection{The positive effect of globalisation on spreading animal welfare standards}

We have discussed the prospects of globalisation on the international implementation of alternative approaches earlier (Bottini et al., 2007). Here, we will limit ourselves to reflecting on the similarity in arguments made by David Vogel with regard to environmental standards (Vogel, 1995): He argues that although trade liberalisation has undermined national regulatory sovereignty, it also globalises regulatory policy-making by exporting standards as well as goods. The primary challenge is whether a country should be allowed to restrict the sale of a product on the basis of how it was produced outside its legal jurisdiction. In case of environmental legislation the classical dispute was about the US ban on tuna from Mexico which did not fulfill US standards for dolphin protection. In 1991, the GATT (General Agreement on Tariffs and Trade of 1947), the predecessor of the
World Trade Organisation (WTO) created in 1995, ruled against the higher protective standards of the US. It will be extremely important to see whether the animal protection standards of the $7^{\text {th }}$ amendment of the cosmetics directive will lead to a similar WTO ruling. This could have happened already, because since September 2004 end-product testing of cosmetics should preclude marketing in Europe, as should the use of ingredients tested on animals where alternatives were available. However, products are still being entered into world markets that have conflicting regulations, without any known legal challenge. Perhaps this will change after the deadline of March 2009. Challenges will likely arise from animal welfare NGOs (as we have seen in the field of environmental legislations) instead of in form of national prosecution.

Independent of any cost/benefit analysis, the attractiveness of the European cosmetics market has instigated discussions on the convergence of legislation in many countries. If Europe can demonstrate the feasibility of its novel approach, others are likely to follow. This would follow the argument of Vogel, who does not see free trade impairing higher national standards but favouring their export, because:

- producers who operate in many markets have a strong interest in making national product standards more similar in order to reduce their production costs.

- the compatibility between trade expansion and protective regulation has to do with the structure and authority of international institutions.

- the increase in regulation has not been more disruptive to trade [due to the link] with increasing international ... treaties and agreements.

We will see whether this is wishful thinking or will in fact lead to the globalisation of animal protection standards.

\subsection{Refining research techniques}

Life science is one of the fastest growing disciplines: its knowledge base is said to double every 5 to 7 years. Especially the key technologies of alternative approaches, i.e. cell culture and computer-based modelling, have undergone dramatic developments, often referred to as the informatics and biotech revolution. Science aims to stay on the cutting-edge with many mechanisms, such as peer-review, forcing the scientists to stay up to date. The backlog of overdue method renewal in regulatory toxicology is most remarkable, since hardly any scientific field continues to use experimental set-ups developed more than 40 years ago. This reflects the absence of scientific control mechanisms, such as publication, peer-review, repeat experiments and competitive funding in this field.

However, the development of (bio-)informatics and biotechnologies and their commercialisation creates new momentum. Companies trying to develop their markets challenge established approaches. They aim to take a share of the agent discovery area (most open to innovation), basic research, as well as the regulatory testing market (most resistant to change). If the above estimates are realistic, we are talking about markets worth several b€ per year in Europe alone. Many start-ups targeted new therapies first but then discovered that developing methods for 
alternative testing can possibly be quicker or provide additional revenue: prominent examples include artificial skin originally developed for burn patients, stem cell technologies originally targeting transplant indications, or novel liver cells often developed for patients with liver failure. With fresh ideas, professional solutions and the clout to drive their methods to success, especially small/medium enterprises have changed the field of alternative approaches over the last few years.

\subsection{Increasing standards of animal welfare}

Animal welfare standards are rising continuously, interestingly not only because of animal welfare considerations, but because their impact on the quality of results is increasingly recognised. This includes a clear definition of the experimental animal (defined inbred and outbred strains), exclusion of confounders such as latent infections (specified pathogen-free, SPF) and using sufficiently large and enriched cage environments. The positive effect of these measures on experimental design and outcome has been documented on various occasions. The various professional organisations, but also funding bodies and journals requesting certain standards to be explicitly adhered to, have helped a lot toward implementing and developing them further. Last but not least, the animal welfare directive 86/609/EEC has helped a lot to raise and harmonise animal welfare in the EU, and expectations are high that the current revision will further augment this.

\subsection{Activity of animal welfare groups}

Similar to the environmental field, animal welfare is characterised by large activist groups that are aligned internationally and are increasingly accepted as stakeholders in legislative and regulatory processes. Noteworthy, not only by creating awareness and shaping public opinion as well as lobbying to politicians have they promoted animal welfare standards and legislation, but they also play an important role in the process as watch-dogs for their implementation. It is likely that, similar to the environmental field, especially the European Court of Justice will further influence the interpretation and application of legislative standards via cases brought forward by such organisations. This is especially important since the EU has no executive forces for the implementation and the monitoring of legal provisions.

\subsection{Increasing demand for regulation}

Europe has taken over the role of pacemaker for legislative standards for the environment. Recent initiatives in the chemicals, food and plant protection product area give evidence of this role. For animal welfare standards, the leading role of EU legislation is obvious from the 1986 legislation binding all Member States and, as a horizontal legislation, also impacting on various other political frameworks. In contrast, the US animal welfare legislation dates back to 1967 and desperately awaits an update.

The two key legislations impacting on the development of alternative methods, i.e. REACH and the $7^{\text {th }}$ amendment of the cosmetics directive have already been discussed here extensively. The credibility of such legislations depends strongly on the accompanying measures, such as research funding and creation of institutions for the validation and agencies for the implementation of novel approaches. Especially European funding (with about $25 \mathrm{~m} €$ by the EU and $19 \mathrm{~m} €$ by Member State organisations) is not matched by other economic regions. Considering the market opportunities as well as the regulatory needs summarised earlier, this appears to be a good investment, actually a rather small investment given the annual turnover in this field and the enormous impact better regulation could have.

\subsection{Positive effect of regulation on innovation}

The MIT-economist Michael E. Porter has most prominently put forward the hypothesis that regulations stimulate innovation (Porter, 1991). The concept has been challenged for chemical industry and REACH (Frohwein and Hansjurgens, 2005), but only with regard to the substitution of substances. However, a principal goal of REACH (article 1) is also the development of new alternative methods; here, the "Porter effect" might spring into action, just as the $7^{\text {th }}$ amendment to the cosmetics directive had a positive impact (Hartung, 2008b). The information demands of REACH focus precisely on toxicological endpoints that are complementary to those of the $7^{\text {th }}$ amendment or, more precisely, those only required for its later deadline in 2013, which are - with the notable exception of repeated dose toxicity - only rarely required for cosmetic ingredients. Thus, together, the two legislations create pressure to drive innovation in the entire spectrum of toxicological endpoints.

\subsection{EPAA as a public/private partnership}

We have discussed earlier the public-private partnership EPAA (the European Partnership on Alternative Approaches to Animal Testing, http://ec.europa.eu/enterprise/epaa/index_en.htm) (Hartung, 2008b). A public-private partnership is a government service or private business venture funded and operated through a partnership of government with one or more private sector companies. EPAA was launched in November 2005 during the "Europe Goes Alternative" conference as a joint initiative between the Commission services, more than 30 companies and 7 trade federations. It is based on a commitment to the 3R's Declaration (reduce, refine $\&$ replace animal testing). In general, a partnership is a type of business entity, in which partners share with each other the profits or losses of the business undertaking in which all have invested. Thus, the name might be somewhat misleading, since EPAA sees itself more as a collaboration platform and major budgets have not been created. It enjoys the fullhearted support of the initiating Commissioners Gunter Verheugen (Enterprise and Industry), "The agreement underlines that the EU is in the lead for animal protection. We do not only wish to reduce animal testing, but also want to bring it to an end in the long run. Anyway, alternative testing methods are innovations, which benefit the competitiveness of European industry" and Janez Potočnik (Sciences and Research): "The agreement with different industry sectors is a major step forward in mak- 
ing validated alternative methods available. We will support the partnership by increasing our efforts to support research, development and evaluation of alternative testing methods under the new Research Framework Programme." It is thus an interesting new type of collaboration between the regulating and the regulated community. From what we have observed so far, EPAA has changed the way first competing companies within one sector, then different industrial sectors and lastly industry and the Commission talk to each other and agree on action points to jointly solve the challenge of reducing and finally overcoming animal testing.

\section{Conclusions}

The endeavour to consider animal testing not under scientific or ethical but business considerations reveals a number of stakeholders with significant commercial interests who are affected by the ethical and scientific discussions. Although it was difficult to produce a precise picture, since many figures are not freely available, an interesting picture already emerges on the basis of estimates and extra- and intrapolations. It shows that major industries, trade and workforces are intimately linked to regulation based on animal testing. It becomes clear that this is more than the simple production costs or imposed barriers, but that problems of the quality of current testing also have an impact on decision-taking and regulation of products. This understanding might help to make stakeholders more amenable to thinking more critically about the current procedures, the first step to becoming more amenable to change. Understanding how the status quo is impairing the economy and causing delays and high costs to businesses can be harnessed to a driving force to improve methods with the added bonus of improving animal welfare standards. The calculation of a possible impact on life expectancy of less medical progress caused by precautionary testing, though still somewhat premature, might still show that we are also talking about relevant societal effects in this discussion, not only about lost business opportunities for individual companies.

To close, we are aware that this text represents only a first sketch of an analysis of the economic aspects of animal testing. Some perceived trends might have to be revised, but it is comforting that economists also see their approaches as somewhat limited, to cite Laurence J. Peter (1919-1988): “An economist is an expert who will know tomorrow why the things he predicted yesterday didn't happen today."

\section{References}

(websites as accessed in November/December 2008)

Bottini, A. A., Amcoff, P. and Hartung, T. (2007). Food for thought $\ldots$ on globalization of alternative methods. ALTEX 24, 255-261.

Bremer, S., Pellizzer, C., Hoffmann, S. et al. (2007). The development of new concepts for assessing reproductive toxicity applicable to large scale toxicological programs. Curr.
Pharm. Des. 13, 3047-3058.

CIAA - Confederation of the food and drink industries of the EU (2003). http://www.foodnavigator.com/Product-Categories/Emulsifiers-stabilisers-hydrocolloids/Europe-s-foodindustry-steady

Durodie, B. (2003). The true cost of precautionary chemicals regulation. Risk Analysis 23, 389-398.

European Commission (2006). Regulation (EC) No 1907/2006 of the European Parliament and of the Council of 18 December 2006 concerning the Registration, Evaluation, Authorisation and Restriction of Chemicals (REACH), establishing a European Chemicals Agency, amending Directive 1999/45/ EC and repealing Council Regulation (EEC) No 793/93 and Commission Regulation (EC) No 1488/94 as well as Council Directive 76/769/EEC and Commission Directives 91/155/ EEC, 93/67/EEC, 93/105/EC and 2000/21/EC. Official Journal of the European Union L 396/1, 1-849.

European Commission (2007). Fifth Report from the Commission to the Council and the European Parliament on the Statistics on the number of animals used for experimental and other scientific purposes in the member states of the European Union COM/2007/675 final.http://ec.europa.eu/environment/ chemicals/lab_animals/reports_en.htm

Eurostat (2006). Food: From farm to fork statistics - statistical pocketbook. http://ec.europa.eu/food/resources/publications_en.htm

Eurostat (2008). The manufacture of basic chemicals. Eurostat Statistics in focus 58.

Fleischer, B. (2007). Testing costs and testing capacity according to the REACH requirements - results of a survey of independent and corporate GLP laboratories in the EU and Switzerland. J. Business Chem. 4, 96-114.

Frohwein, T. and Hansjurgens, B. (2005). Chemicals regulation and the Porter hypothesis - a critical review of the new European chemicals regulation. J. Business Chem. 2, 19-36.

Gollier, C. and Treich, N. (2003). Decision-making under scientific uncertainty: the economics of the precautionary principle. J. Risk Uncertainty 27, 77-103.

Griesinger, C., Hoffmann, S., Kinsner-Ovaskainen, A. et al. (2009). Foundations of an Evidence-Based Toxicology. Proceedings of the First International Forum Towards EvidenceBased Toxicology. Conference Centre Spazio Villa Erba, Como, Italy. 15-18 October 2007. Human Exp. Toxicol. (in press).

Gruber, F. P. and Hartung, T. (2004). Alternatives to animal experimentation in basic research. ALTEX 21 Suppl. 1, 3-31.

Hartung, T (2009). Toxicology kissed awake. Nature (in press).

Hartung, T. (2008a). Food for thought ... on animal tests. ALTEX 25, 3-9.

Hartung, T. (2008b). Food for thought ... on alternative methods for cosmetics safety testing. ALTEX 25, 147-162.

Hartung, T and Koeter, H. (2008). Food for thought ... on alternative methods for food safety testing. ALTEX 25, 259-264 (in press).

Hartung, T. and Leist, M. (2008). Food for thought ... on the evolution of toxicology and phasing out of animal testing. ALTEX 25, 91-96. 
Höfer T., Gerner, I., Gundert-Remy, U. et al. (2004). Animal testing and alternative approaches for the human health risk assessment under the proposed new European chemicals regulation. Arch. Toxicol. 78, 549-564.

Hoffmann, S. and Hartung, T. (2005). Diagnosis: Toxic! - Trying to apply approaches of clinical diagnostics and prevalence in toxicology considerations. Tox. Sci. 85, 422-428.

Hoffmann, S. and Hartung, T. (2006). Towards an evidencebased toxicology. Human Exp. Toxicol. 25, 497-513.

Kola, I. and Landis, J. (2004). Can the pharmaceutical industry reduce attrition rates? Nature Rev. Drug Discov. 3, 711-715.

Lantra (2006). The sector skills council for the environmental and land-based sector, sector skills agreement Animal Technology, Annex. http://www.lantra.co.uk

Leist, M., Hartung, T. and Nicotera, P. (2008). The dawning of a new age of toxicology. ALTEX 25, 103-114.

Le Monde diplomatique (2006). Atlas der Globalisierung. 2nd edition, Berlin: Taz.

Litchfield, M. H. (2005). Estimates of acute pesticide poisoning in agricultural workers in less developed countries. Toxicol. Rev. 24, 271-278.

Lichtenberg, F. (2005a). The impact of new drug launches on longevity: evidence from longitudinal disease-level data from 52 countries, 1982-2001. Int. J. Health Care Finance Economics 5, 47-73.

Lichtenberg, F. (2005b). The effect of access restrictions on the vintage drugs used by Medicaid enrollees. Am. J. Managed Care 11 (special issue), SP7-SP13.

Lichtenberg, F. (2007). Why longevity increased more in some state than others? The role of medical innovation and other factors. Medical Progress Report No. 4, Center for Medical Progress at the Manhattan Institute, 1-31.

Lofstedt, R. E., Fischhoff, B. and Fischhoff, I. R. (2002). Precautionary principles: general definitions and specific applications to genetically modified organisms. J. Policy Analysis Management 21, 381-407.

Majone, G. (2002). The Precautionary Principle and its Policy Implications. J. Common Market Studies 40, 89-109.

MRC-IEH (2001). Testing requirements for proposals under the EC white paper - strategy for a future chemicals policy, (We Report W6). Leicester, UK: MRC IEH.

Pedersen, F., de Bruijn, J., Munn, S. and van Leeuwen, K. (2003). Assessment of additional testing needs under REACH - effects of (Q)SARS, risk based testing and voluntary industry initiatives. http://ecb.jrc.it/DOCUMENTS/REACH/PUB-
LICATIONS/REACH_testing_needs_final.pdf

Plunkett Research. http://www.plunkettresearch.com/Industries/FoodBeverageTobacco/FoodBeverageTobaccoStatistics/tabid/248/Default.aspx

Porter, M. (1991). The competitive advantage of nations. Harvard Business Rev. 1991, March/April, 73-93.

Resnik, D. B. (2003). Is the precautionary principle unscientific? Studies in History and Philosophy of Science Part C: Studies in History and Philosophy of Biological and Biomedical Sciences 34, 329-344.

Taleb, N. N. (2007). The black swan - the impact of the highly improbable. New York: The Random House Publishing Group.

Taylor, K., Gordon, N., Langley, G. and Higgins, W. (2008). Estimates for worldwide laboratory animal use in 2005. ATLA 36, 327-342.

Vogel, D. (1995). Trading up - consumer and environmental regulation in a global economy. Cambridge: Harvard University Press.

Wikipedia (2007). List of countries by nominal GDP for 2007. http://en.wikipedia.org/wiki/List_of_countries_by_GDP_ (nominal)

Jeyaratnam, J. (1990). Acute pesticide poisoning: a major global health problem. World Health Stat. Q. 43, 139-144.

\section{Acknowledgements}

This article is part of the BA with honor thesis of Annemaria A. Bottini. The stimulatory discussions with Dr. Elisabeth Farmaki and Prof. David Ward (both European School of Economics, Milan) are gratefully appreciated.

\section{Correspondence to}

Prof. Thomas Hartung

Doerenkamp-Zbinden-Chair for Evidence-based Toxicology

Center for Alternatives to Animal Testing (CAAT)

Department for Environmental Health Sciences

Johns Hopkins University

111 Market Place, Suite 840

Baltimore, MD 21202-6709

Phone: 410-223-1692

Fax: 410-223-1603

e-mail: THartung@jhsph.edu 